\title{
Effectiveness of maturity of Rubus occidentalis on hyperalgesia induced by acidic saline injection in rats
}

\author{
Geun Joo Choi ${ }^{1}$, Hyun Kang ${ }^{1 *} \mathbb{0}$, Oh Haeng Lee ${ }^{1}$, Eun Jin Ahn ${ }^{1}$, Fletcher A. White ${ }^{2,3}$, Ye Jin Cho', \\ Chong Wha Baek', Yong Hun Jung ${ }^{1}$ and Ji Wung Kwon ${ }^{4}$
}

\begin{abstract}
Background: Rubus occidentalis, also known as black raspberry, contains several bioactive components that vary depending on the maturity of the fruit. The goal of this study was to evaluate the efficacy of immature Rubus occidentalis extract(iROE) on acid-induced hyperalgesia, investigate the mechanism involved, and compare the antihyperalgesic effect of immature and mature ROEs.

Methods: In adult male Sprague-Dawley rats, chronic muscle pain was induced via two injections of acidic saline into one gastrocnemius muscle. To evaluate the dose response, the rats were injected intraperitoneally with $0.9 \%$ saline or $\operatorname{ROE}(10,30,100$, or $300 \mathrm{mg} / \mathrm{kg}$ ) following hyperalgesia development. To evaluate the mechanism underlying iROE-induced analgesia, the rats were injected intraperitoneally with saline, yohimbine $2 \mathrm{mg} / \mathrm{kg}$, dexmedetomidine $50 \mu \mathrm{g} / \mathrm{kg}$, prazosin $1 \mathrm{mg} / \mathrm{kg}$, atropine $5 \mathrm{mg} / \mathrm{kg}$, mecamylamine $1 \mathrm{mg} / \mathrm{kg}$, or naloxone $5 \mathrm{mg} / \mathrm{kg} 24 \mathrm{~h}$ after hyperalgesia development, followed by iROE $300 \mathrm{mg} / \mathrm{kg}$ administration. To compare immature versus mature ROE, the rats were injected with mature ROE $300 \mathrm{mg} / \mathrm{kg}$ and immature ROE $300 \mathrm{mg} / \mathrm{kg}$ after hyperalgesia development. For all experiments, the mechanical withdrawal threshold(MWT) was evaluated using von Frey filaments before the first acidic saline injection, $24 \mathrm{~h}$ after the second injection, and at various time points after drug administration. Data were analysed using multivariate analysis of variance(MANOVA) and the linear mixed-effects model(LMEM). We compared the MWT at each time point using analysis of variance with the Bonferroni correction.
\end{abstract}

Results: The iROE $300 \mathrm{mg} / \mathrm{kg}$ injection resulted in a significant increase in MWT compared with the control, iROE $30 \mathrm{mg} / \mathrm{kg}$, and iROE $100 \mathrm{mg} / \mathrm{kg}$ injections at ipsilateral and contralateral sites. The iROE injection together with yohimbine, mecamylamine, or naloxone significantly decreased the MWT compared with iROE alone, whereas ROE together with dexmedetomidine significantly increased the MWT. According to MANOVA, the effects of immature and mature ROEs were not significantly different; however, the LMEM presented a significant difference between the two groups.

Conclusions: Immature R. occidentalis showed antihyperalgesic activity against acid-induced chronic muscle pain, which may be mediated by the $\mathrm{a}_{2}$-adrenergic, nicotinic cholinergic, and opioid receptors. The iROE displayed superior tendency regarding analgesic effect compared to mature ROE.

Keywords: Analgesics: Black raspberry, Chronic pain, Hyperalgesia, Rubus occidentalis

*Correspondence: roman00@naver.com

1 Department of Anesthesiology and Pain Medicine, Chung-Ang

University College of Medicine, 84 Heukseok-ro, Dongjak-gu, Seoul 06911,

Republic of Korea

Full list of author information is available at the end of the article

\section{Background}

Chronic musculoskeletal pain has a considerable influence on physical, emotional, psychological, and social aspects with only few effective therapeutic strategies 
available for pain control [1]. Currently, multimodal therapeutic approaches using various medications and techniques are recommended for chronic pain control; however, this condition remains difficult to treat. The pharmacological regimen for pain management tends to emphasise opioid sparing. Moreover, pharmacological strategies for pain control should be safe to enable their use over a long duration. In this regard, recently, there is a growing interest in therapeutic approaches based on food for the management of chronic pain. Indeed, several investigations have suggested the health benefits of functional foods or nutraceuticals and their potential for relieving chronic pain [2].

Rubus occidentalis, also known as black raspberry, is being recognised for its anti-inflammatory, antinociceptive, and antioxidant properties [3, 4]. These properties of $R$. occidentalis are attributed to its content of anthocyanins, ellagic acid, and other phenolic compounds, the bioactivities of which vary depending on the maturity of the fruit $[3,5,6]$. In a study on pre-matured black raspberry, immature $R$. occidentalis appeared to produce a high content of phenolic compound, flavonoids, and vitamin $\mathrm{C}$, implying the potential to be used as a functional food or medicinal substance derived from nature [5].

Previously, we investigated the effect of mature $R$. occidentalis on chronic pain model in rats [7] and there has been no study regarding the effect of immature $R$. occidentalis on chronic pain and associated mechanism yet. Therefore, we hypothesise that the immature form of $R$. occidentalis will attenuate chronic musculoskeletal pain in current study. To identify the relationship between chronic musculoskeletal pain and immature $R$. occidentalis, we developed a rat model with hyperalgesia induced by repeated intramuscular injection of acidic saline; immature $R$. occidentalis extract (iROE) was administered intraperitoneally. The primary outcome was to assess the analgesic property of iROE. The secondary outcome was to investigate the potential mechanism underlying its analgesic activity. Additionally, we compared the analgesic effect between immature and mature $R$. occidentalis.

\section{Methods}

This randomised controlled experimental study was performed in accordance with the National Institutes of Health Guide for the Care and Use of Laboratory Animals and described according to the Animal Research: Reporting In Vivo Experiments (ARRIVE) guidelines $[8,9]$.

\section{Preparation of the immature or mature $R$. occidentalis extract}

The iROE and mature $R$. occidentalis extract (mROE) were provided by the Gochang Black Raspberry Research Institute of South Korea.

In June 2016, immature fruit with green colour was harvested within post-bloom 28 days and mature fruit with dark red colour was harvested after post-bloom 38 days from the Gochang (Jeollabuk-Do) area of South Korea. Both immature and mature $R$. occidentalis were authenticated by Dr. Ji Wung Kwon, a research director of Gochang Black Raspberry Research Institute, where voucher specimens of the two were deposited (specimen voucher number: GBRI-17, 18).

The following two extract of $R$. occidentalis fruit: iROE and $\mathrm{mROE}$ were prepared. In brief, immature fruit $(1 \mathrm{~kg})$ and mature fruit $(1 \mathrm{~kg})$ were pulverized and extracted twice with $50 \%$ ethanol (10 times weight of each fruit) at $80^{\circ} \mathrm{C}$ for $2 \mathrm{~h}$ by using a reflux condenser. The extract was filtered and concentrated, and the concentrated was lyophilised in a freezer-dryer and stored at $-20^{\circ} \mathrm{C}$ before use. The extract yields were $17.2 \%$ of immature fruit and $7.5 \%$ of mature fruit, respectively. Since the ethanol was effective and stable solvent for plant extraction in many studies on the Rubus species, $50 \%$ ethanol for fruit extraction was used. All procedures were conducted under sterilized condition and stored $\mathrm{iROE}$ and $\mathrm{mROE}$ were used just before intraperitoneal administration.

\section{Study animals}

The experiment was performed in the Animal Research Laboratory of Chung-Ang University and was approved by the Institutional Animal Care and Use Committee at Chung-Ang University (no. 2017-00107). Adult male Sprague-Dawley rats (250-300 g; Coretec, Seoul, Korea) were housed individually in cages in a temperature-controlled room $\left(22^{\circ} \mathrm{C}\right)$ and fed a standard laboratory diet and tap water ad libitum. They were maintained under a 12-h light/dark cycle (lights on from 8:00a.m. to $8: 00 \mathrm{p} . \mathrm{m}$.) and acclimated to the housing facilities for 1 week before the experimental procedures. Females were not included because hormonal fluctuations may have affected the pain threshold [10]. Rats with any abnormalities were excluded. All animals were euthanized by placing rats in the transparent induction chamber and carbon dioxide $\left(\mathrm{CO}_{2}\right)$ inhalation after completing the experiment [11]. Specifically, we used a compressed $\mathrm{CO}_{2}$ gas cylinder with a pressure-reducing regulator and a calibrated flow meter. We placed rats in the chamber without pre-charging the chamber and introduced $100 \% \mathrm{CO}_{2}$ at flow rate of 3 to 71 per minute, equivalent to a fill rate of 30 to $70 \%$ of the $10-1$ chamber volume per minute. 


\section{Induction of hyperalgesia in the muscle}

All the experiments were performed between $8 \mathrm{a} . \mathrm{m}$. and 1 p.m. to avoid diurnal variation and under sterile conditions by an investigator who was blinded to the group allocation of the individual rats. Hyperalgesia was induced in the muscle as described previously [12], with minor modifications on injection interval in the reported technique. Briefly, rats were anaesthetised with $1-4 \%$ isoflurane in $100 \%$ oxygen and injected with $100 \mu \mathrm{L}$ of pH 4.0 preservative-free sterile saline into a lateral gastrocnemius muscle on day 0 and again on day 3 .

\section{Group allocation and blinding}

To evaluate the antinociceptive effect of iROE and elucidate the mechanism underlying the iROE-induced analgesia, the rats were randomly divided into groups according to the respective experiment. Random assignment was based on a table generated using the PASS software, version 11 (NCSS, Kaysville, UT, USA), applying Wei's urn model. The randomisation code was generated by a statistician who was not otherwise involved in the study. For allocation concealment, another investigator who was not involved in this study prepared syringes containing the study drugs for the experiments. The study drugs were dissolved in normal saline, and the intraperitoneal (IP) injection volume was $2 \mathrm{~mL}$. The syringes were covered with an opaque tape and numbered sequentially according to a randomised list of experiments. The prepared syringes were delivered to a researcher in charge of surgery. This researcher, who was blinded to the group assignment, participated only in the peritoneal injection.

\section{Experiment 1: Evaluation of the antinociceptive effect of iROE: Dose-response test}

The purpose of Experiment 1 was to evaluate the antinociceptive effect of iROE on the mechanical hyperalgesia induced by repeated intramuscular injections of acidic saline. Fifty rats were randomly assigned to 1 of 5 groups of 10 rats (groups administered control or 10,30,100, or $300 \mathrm{mg} / \mathrm{kg}$ iROE). Various doses of iROE or normal saline was injected intraperitoneally $24 \mathrm{~h}$ after the second injection of acidic saline. The doses of ROE were referred on the amount used in our previous experimental study [7] and fixed based on the logarithmic increase.

\section{Experiment 2: Elucidation of the mechanism mediating iROE-induced analgesia}

The purpose of Experiment 2 was to examine whether the antinociceptive effect of iROE was mediated via $\alpha$ (1 and 2)-adrenergic, cholinergic (nicotinic and muscarinic), and/or opioid receptors. Seventy rats were randomly assigned to 1 of 7 groups of 10 rats, which were injected with either normal saline (iROE $300 \mathrm{mg} / \mathrm{kg}$ alone) or yohimbine $2 \mathrm{mg} / \mathrm{kg}$, dexmedetomidine $50 \mu \mathrm{g} /$ $\mathrm{kg}$, prazosin $1 \mathrm{mg} / \mathrm{kg}$, atropine $5 \mathrm{mg} / \mathrm{kg}$, mecamylamine $1 \mathrm{mg} / \mathrm{kg}$, or naloxone $5 \mathrm{mg} / \mathrm{kg}, 24 \mathrm{~h}$ after the development of hyperalgesia. Ten minutes later, $300 \mathrm{mg} / \mathrm{kg}$ iROE was injected intraperitoneally. Previous research [13-16] supported the use of drugs to elucidate the possible involvement of those receptor systems. Sigma Aldrich provided us with the study drugs (U.S.A.).

\section{Experiment 3: Comparison of the antinociceptive effect of $\mathrm{iROE}$ and $\mathrm{mROE}$}

The purpose of Experiment 3 was to evaluate the difference in the antinociceptive effect of iROE and mROE on the mechanical hyperalgesia induced by repeated intramuscular injections of acidic saline. Two groups of 10 rats each were administered mROE $300 \mathrm{mg} / \mathrm{kg}$ and iROE $300 \mathrm{mg} / \mathrm{kg}$, respectively. The dose of immature and mature ROEs was determined based on the results from dose response test from present and previous studies.

\section{Experiment 4: Comparison of the antinociceptive effect of iROE versus the positive control}

The purpose of Experiment 4 was to assess the validity of the present study. The group receiving the peak effective dosage of iROE $(300 \mathrm{mg} / \mathrm{kg})$ for antinociception was compared to a positive-control group receiving intraperitoneal ketolorac $(30 \mathrm{mg} / \mathrm{kg})$.

\section{Experiment 5: Assessment of motor impairment}

To identify the effect of iROE on motor function or the sedative effect of iROE, we used an accelerating Rota-rod treadmill (Jeung Do Bio \& Plant Co., Ltd., Seoul, Korea). This test is useful for determining motor impairment caused by pharmacological agents such as central nervous system depressants. Eighteen rats were randomly assigned to one of three groups of six rats: iROE $300 \mathrm{mg} /$ $\mathrm{kg}$ group, $\mathrm{mROE} 300 \mathrm{mg} / \mathrm{kg}$ group, and control group. To adapt the rats to the treadmill test, 2 sets of training trials were performed 2 days and 1 day before the first injection. The rats were injected intraperitoneally with $300 \mathrm{mg} /$ $\mathrm{kg}$ iROE, mROE, or normal saline $24 \mathrm{~h}$ after the second injection of acidic saline. Two hours after the injection of iROE, mROE, or normal saline, the Rota-rod test was performed. Specifically, the rats were placed on the Rotarod running at a speed gradually increasing from 1 to 18 rotations per minute (rpm) for $120 \mathrm{~s}$ and maintained for another $30 \mathrm{~s}$ at $18 \mathrm{rpm}$ [12]. The time point at which the rats fell off the Rota-rod was noted.

\section{Behavioural measurements}

For experiments 1, 2, 3, and 4, individual rats were placed on an elevated plastic mesh floor $(8 \times 8 \mathrm{~mm}$ 
perforations) under an overturned clear plastic cage $(21 \times 27 \times 15 \mathrm{~cm})$ and allowed to acclimate for $15 \mathrm{~min}$. The rats were then evaluated to determine their withdrawal thresholds to mechanical stimuli using von Frey filaments (Stoelting Co., IL, USA). The filaments were applied vertically to the plantar aspect of the hind paw by administering sufficient pressure to gently bend the filament. Filaments with bending forces of 4, 9, 20, 59, $78,98,147$, and $254 \mathrm{mN}$ were progressively applied until the hind paw was withdrawn or a bending force of $254 \mathrm{mN}$ (the cut-off value) was reached. Each filament was applied three times at intervals of $3 \mathrm{~min}$. The lowest bending force that caused paw withdrawal after the application of the filament was considered the mechanical withdrawal threshold (MWT) of the hind paw. The full lifting of the plantar surface off the mesh floor was considered a positive withdrawal response and partial lifting, walking, hunching, stretching, or licking was not included. After a response was observed, filaments with higher and lower bending forces were utilised to confirm the MWT. The MWT assessment was performed by a well-trained investigator who was unaware of the group allocation.

The MWT was assessed according to the following schedule: before the first injection (BI); $24 \mathrm{~h}$ after the second injection (AI); and $15 \mathrm{~min}, 30 \mathrm{~min}, 45 \mathrm{~min}$, $60 \mathrm{~min}, 80 \mathrm{~min}, 100 \mathrm{~min}, 120 \mathrm{~min}, 24 \mathrm{~h}, 48 \mathrm{~h}$, and 7 days after the injection of the test drugs. The area under the curve (AUC) values were obtained for $120 \mathrm{~min}$ (from AI to 120 min after the injection of the test drugs).

\section{Statistical analysis}

Data were analysed using analysis of variance (ANOVA), one-way Wilk's lambda multivariate analysis of variance (MANOVA) followed by post hoc t-test or univariate ANOVA with the Bonferroni correction and linear mixed-effects model. Individual measurements are expressed as the means \pm standard errors in the figures and were analysed using SPSS 23.0 (IBM Corp., Armonk, NY, USA). A $P$ value of 0.05 or less was considered statistically significant. A detailed description of the statistical analysis is provided in the supplementary file.

\section{Results \\ Study animals}

All of the rats completed the present study. Throughout the experimental period, the rats remained well-groomed and appeared to ingest a normal amount of food and water. All rats completed the study and no complications were observed.

\section{Evaluation of the antinociceptive effect of iROE: Dose-response test}

The results of MANOVA at the ipsilateral and contralateral sites showed a statistically significant difference among the groups $(\mathrm{F}(48,133.010)=1.529, P=0.031$ : Wilk's lambda $=0.184$, partial $\eta^{2}=0.345$ and $F(48$, $133.010)=1.491, P=0.039$ : Wilk's lambda $=0.190$, partial $\eta^{2}=0.339$. Figure $1 \mathrm{a}$ and $\mathrm{b}$ presents the changes in the MWT at the ipsilateral and contralateral sites established at the baseline; immediately after injection; and $15 \mathrm{~min}, 30 \mathrm{~min}, 45 \mathrm{~min}, 60 \mathrm{~min}, 80 \mathrm{~min}, 100 \mathrm{~min}$, $120 \mathrm{~min}, 24 \mathrm{~h}, 48 \mathrm{~h}$, and 7 days after the administration of iROE. For both the ipsilateral and contralateral sites, the MWT values at $15,30,45$, and 60 min in the group administered iROE $300 \mathrm{mg} / \mathrm{kg}$ were significantly higher than those in the control, iROE $100 \mathrm{mg} / \mathrm{kg}$, and iROE $30 \mathrm{mg} / \mathrm{kg}$ groups. The MWT values at $15,30,45$, and $60 \mathrm{~min}$ in the $100 \mathrm{mg} / \mathrm{kg}$ group were significantly higher than those in the control group for both the ipsilateral and contralateral sites. The MWT at $45 \mathrm{~min}$ in the iROE $100 \mathrm{mg} / \mathrm{kg}$ group for the ipsilateral site and the MWT at 30 and $45 \mathrm{~min}$ in the iROE $100 \mathrm{mg} / \mathrm{kg}$ group for the contralateral site were significantly higher than those in the iROE $30 \mathrm{mg} / \mathrm{kg}$ group.

The AUC values showed significant differences between the groups injected at the ipsilateral and contralateral sites $(F[4,45]=12.153, P<0.001$ and $F[4$, $45]=7.504, \quad P<0.001)$. Compared with the control group, the AUC values at the ipsilateral site were significantly higher in the iROE $30 \mathrm{mg} / \mathrm{kg}$, iROE $100 \mathrm{mg} /$ $\mathrm{kg}$, and iROE $300 \mathrm{mg} / \mathrm{kg}$ groups (MD 40.04; 95\% CI 0.27 to $79.81 ; P=0.048$, MD $64.60 ; 95 \%$ CI 24.83 to 104.37 ; $P<0.001$, MD 90.01; 95\% CI 50.24 to $129.78 ; P<0.001$, respectively) and the AUC values at the contralateral site were significantly higher in the iROE $100 \mathrm{mg} / \mathrm{kg}$, and iROE $300 \mathrm{mg} / \mathrm{kg}$ groups(MD 44.29; 95\% CI 0.00 to $88.57 ; P=0.050$, MD 75.28 ; $95 \%$ CI 30.99 to 119.56 ; $P<0.001$, respectively).

The LMEM showed a significant difference between the groups injected at the ipsilateral and contralateral sites $(\mathrm{F}[4,522.85]=33.540, P<0.001$ and $\mathrm{F}[4$, $494.01]=24.454, P<0.001)$. The MWT in the iROE $10 \mathrm{mg} / \mathrm{kg}$, iROE $30 \mathrm{mg} / \mathrm{kg}$, iROE $100 \mathrm{mg} / \mathrm{kg}$, and iROE $300 \mathrm{mg} / \mathrm{kg}$ groups was significantly higher than that in the control group at the ipsilateral (MD 0.15; 95\% CI 0.05 to $0.25 ; P=0.030, \mathrm{MD} 0.23 ; 95 \%$ CI 0.13 to 0.33 ; $P<0.001$, MD $0.40 ; 95 \%$ CI 0.30 to $0.50 ; P<0.001$, MD $0.54 ; 95 \%$ CI 0.44 to $0.64 ; P<0.001$, respectively) and contralateral sites (MD 0.10; $95 \%$ CI 0.00 to 0.21 ; 

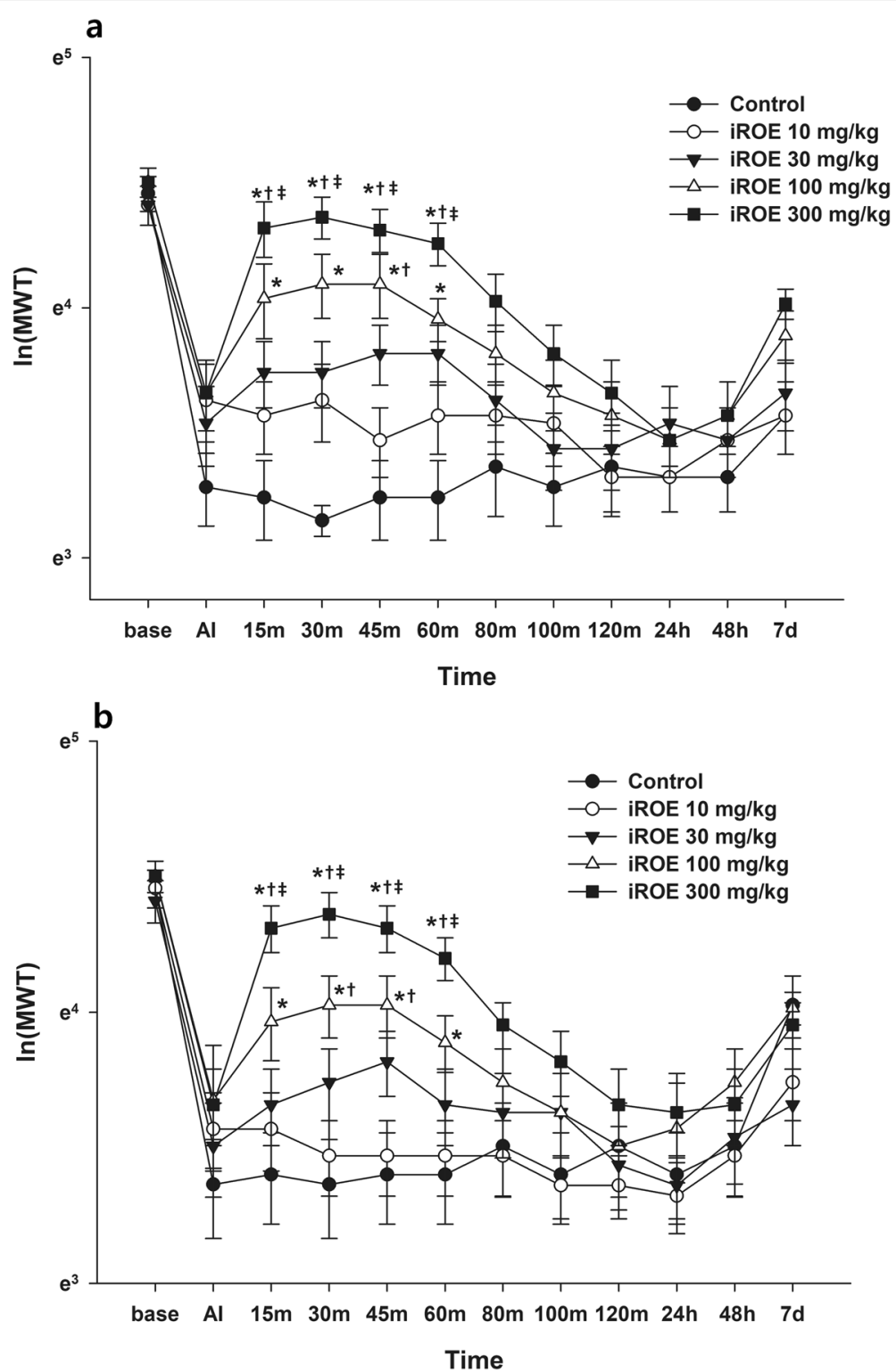

Fig. 1 Antinociceptive effect of immature Rubus occidentalis extract (iROE). a ipsilateral site, b contralateral site. Al: immediately after injection. For statistical analysis, one-way Wilk's lambda multivariate analysis of variance followed by post hoc univariate ANOVA with the Bonferroni correction and linear mixed-effects model was used. ${ }^{*} P<0.05$ compared with the control group, $+P<0.05$ compared with the iROE $10 \mathrm{mg} / \mathrm{kg}$ group, $\neq P<0.05$ compared with the $\mathrm{ROE} 30 \mathrm{mg} / \mathrm{kg}$ group

$P=0.049$, MD $0.28 ; 95 \%$ CI 0.17 to $0.38 ; P<0.001, \mathrm{MD}$ $0.44 ; 95 \%$ CI 0.34 to $0.54 ; P<0.001$, respectively).

\section{Elucidation of the mechanism mediating iROE-induced analgesia}

The results of MANOVA at the ipsilateral and contralateral sites showed a statistically significant difference between the groups $(F(72,288.72)=2.906$, $P<0.001$ : Wilk's lambda $=0.052$, partial $\eta^{2}=0.390$ and $\mathrm{F}(72,288.72)=1.863, P<0.001:$ Wilk's lambda $=0.125$, partial $\left.\eta^{2}=0.293\right)$. For both the ipsilateral and contralateral sites, the MWT values significantly decreased at 15 , $30,45,60,80,100$, and $120 \mathrm{~min}$ in the yohimbine group and increased at 100 and $120 \mathrm{~min}$ in the dexmedetomidine group (Fig. 2a and b). The MWT values significantly decreased from at $15,30,45,60,80,100$, and $120 \mathrm{~min}$ in the naloxone group for both the ipsilateral and contralateral sites and, in the mecamylamine group, decreased at $30,45,100$, and $120 \mathrm{~min}$ at the ipsilateral site and at 30, 45 , and $120 \mathrm{~min}$ at the contralateral site (Fig. $3 \mathrm{a}$ and b). 

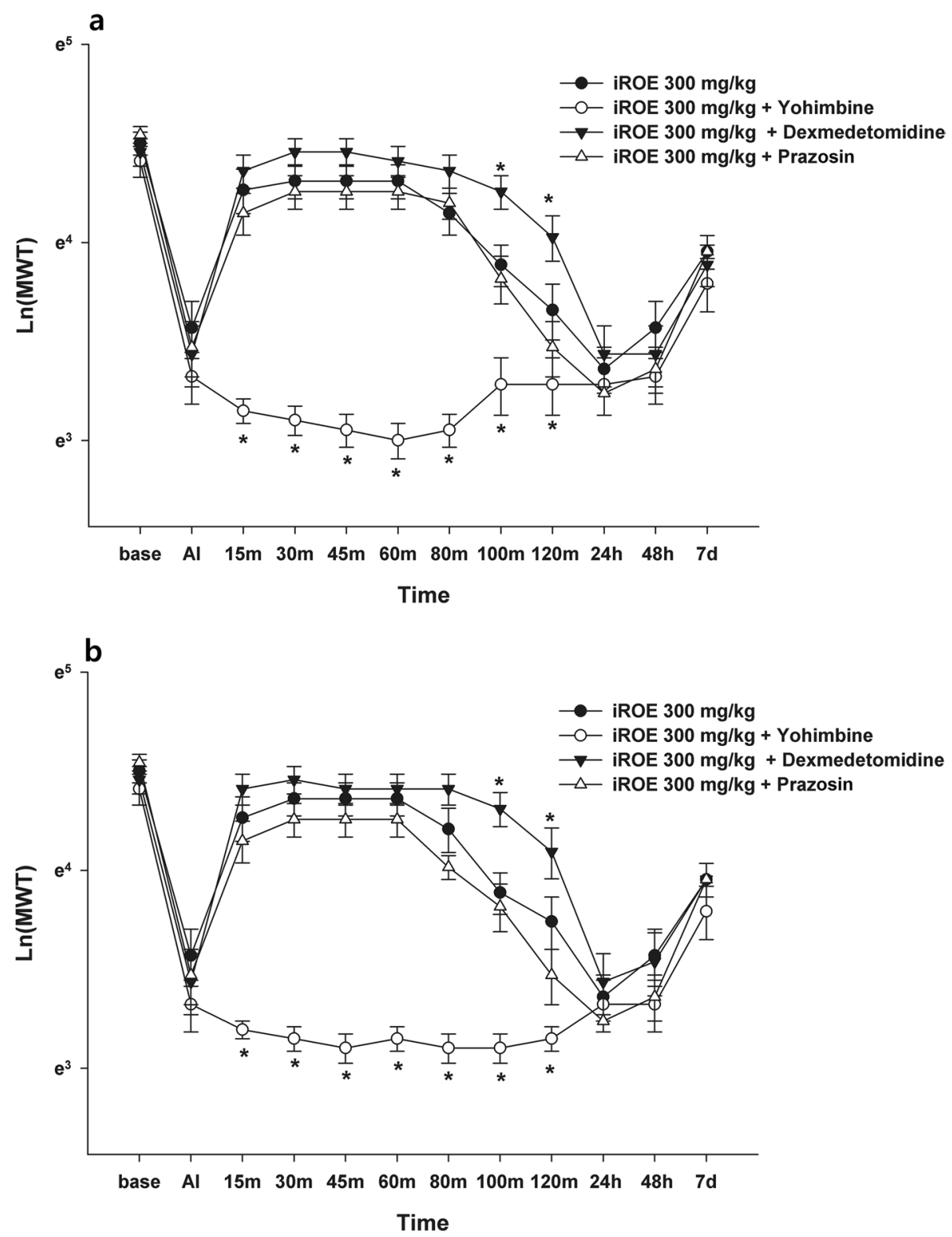

Fig. 2 Antinociceptive mechanism of immature Rubus occidentalis extract (iROE) together with yohimbine, prazosin, or dexmedetomidine. a ipsilateral site, $\mathbf{b}$ contralateral site. Al: immediately after injection. For statistical analysis, one-way Wilk's lambda multivariate analysis of variance followed by post hoc univariate ANOVA with the Bonferroni correction and linear mixed-effects model was used. ${ }^{*} P<0.05$ compared with the iROE $300 \mathrm{mg} / \mathrm{kg}$ group

The LMEM showed a significant difference between the groups injected at the ipsilateral and contralateral sites $(\mathrm{F}[6,773.90]=82.409, P<0.001$ and $\mathrm{F}[6,786.48]=59.483$, $P<0.001)$.

Compared with the MWT value for the iROE $300 \mathrm{mg} /$ $\mathrm{kg}$ group, the MWT values were lower in the yohimbine, atropine, mecamylamine, and naloxone groups for both the ipsilateral (MD -0.70; $95 \% \mathrm{CI}-0.79$ to -0.61 ; $P<0.001$, MD $-0.10 ; 95 \%$ CI -0.20 to $-0.01 ; P=0.033$,
MD -0.12; $95 \%$ CI -0.22 to $-0.03 ; P=0.011$, MD -0.58 ; 95\% CI -0.67 to $-0.49 ; P<0.001$, respectively) and contralateral sites (MD $-0.61 ; 95 \% \mathrm{CI}-0.71$ to -0.52 ; $P<0.001$, MD $-0.13 ; 95 \% \mathrm{CI}-0.22$ to $-0.03 ; P=0.010$, MD - $0.15 ; 95 \%$ CI -0.25 to $-0.05 ; P=0.002$, MD -0.53 ; $95 \% \mathrm{CI}-0.62$ to $-0.43 ; P<0.001$, respectively). The MWT in the dexmedetomidine group at the ipsilateral site was higher than that in the iROE $300 \mathrm{mg} / \mathrm{kg}$ group (MD 0.10; 95\% CI 0.01 to $0.20 ; P=0.030$ ). There was no 

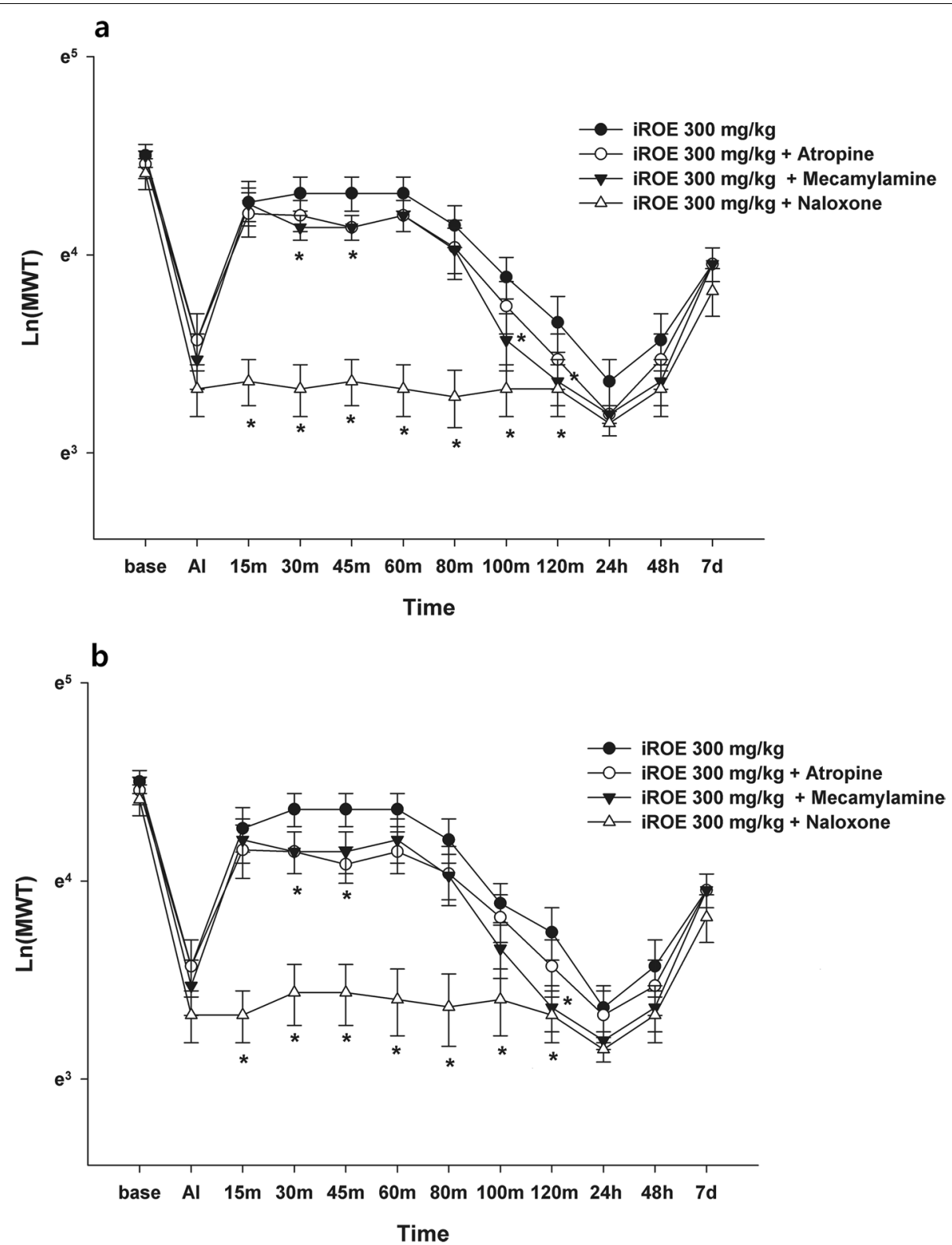

Fig. 3 Antinociceptive mechanism of immature Rubus occidentalis extract (iROE) together with atropine, mecamylamine, or naloxone. a Ipsilateral site, $\mathbf{b}$ Contralateral site. Al: immediately after injection. For statistical analysis, one-way Wilk's lambda multivariate analysis of variance followed by post hoc univariate ANOVA with the Bonferroni correction and linear mixed-effects model was used. ${ }^{*} P<0.05$ compared with the iROE $300 \mathrm{mg} / \mathrm{kg}$ group

evidence of a significant difference in the prazosin group for both the ipsilateral and contralateral sites (MD -0.06; $95 \% \mathrm{CI}-0.15$ to $0.04 ; P=0.240$ and $\mathrm{MD}-0.09 ; 95 \% \mathrm{CI}$ -0.19 to $0.00 ; P=0.061)$ and in the dexmedetomidine group for the contralateral site (MD 0.09; $95 \% \mathrm{CI}-0.00$ to $0.19 ; P=0.062$ ).

The AUC values showed significant differences between the groups injected at the ipsilateral and contralateral sites $(\mathrm{F}[6,63]=59.958, P<0.001$ and $\mathrm{F}[6$, $63]=30.788, P<0.001)$. Compared with the MWT value for the iROE $300 \mathrm{mg} / \mathrm{kg}$ group, the AUC values at the ipsilateral site were significantly lower in naloxone and yohimbine group (MD -85.61; 95\% CI - 112.10 to $-59.12 ; P<0.001$, MD $-105.36 ; 95 \% \mathrm{CI}-131.85$ to $-78.87 ; P<0.001$, respectively) and the AUC values at the contralateral site were significantly lower in naloxone and yohimbine group (MD -85.98; 95\% CI - 123.37 

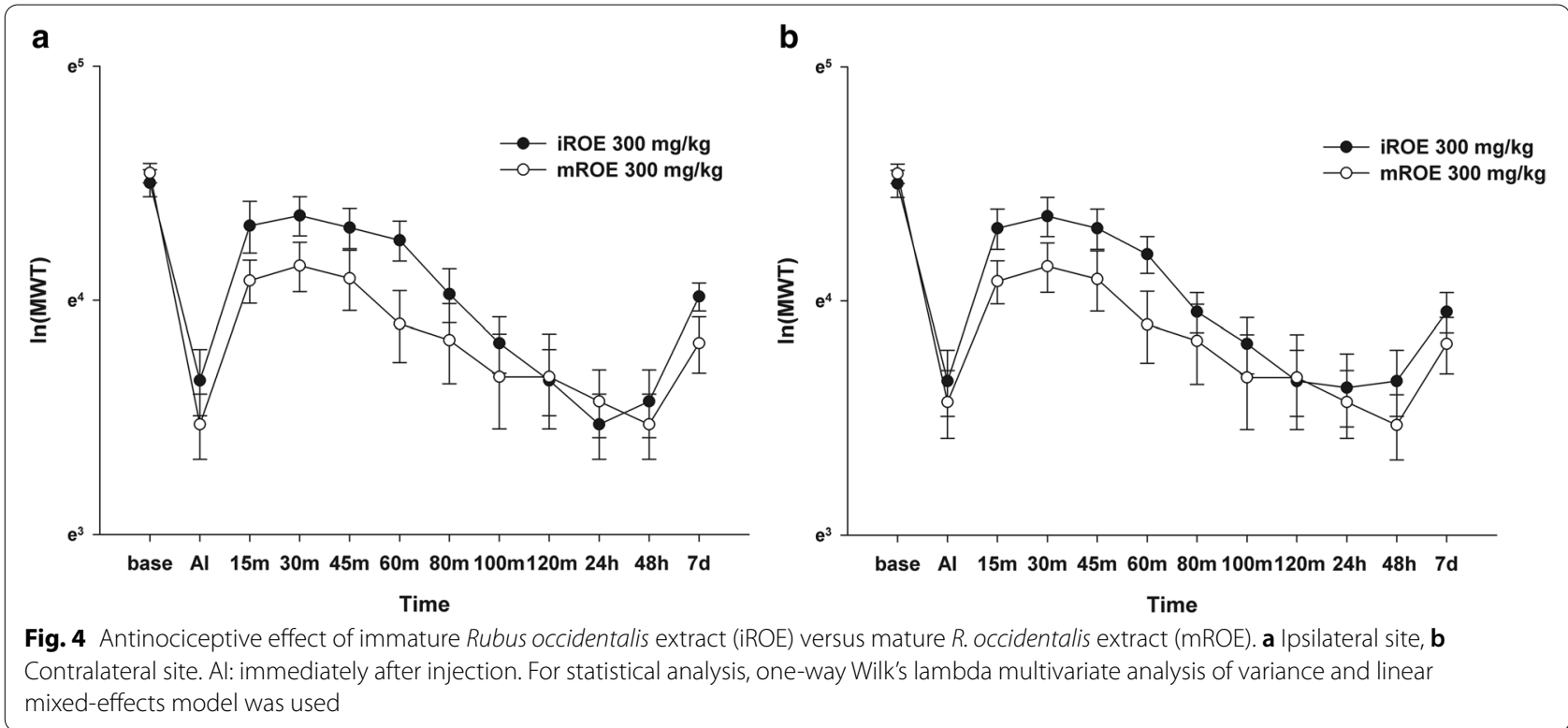

Fig. 4 Antinociceptive effect of immature Rubus occidentalis extract (iROE) versus mature $R$. occidentalis extract (mROE). a lpsilateral site, $\mathbf{b}$ Contralateral site. Al: immediately after injection. For statistical analysis, one-way Wilk's lambda multivariate analysis of variance and linear mixed-effects model was used

to $-50.59 ; P<0.001, \mathrm{MD}-107.20 ; 95 \% \mathrm{CI}-143.59$ to $-70.81 ; P<0.001$, respectively).

\section{Comparison of the antinociceptive effect of iROE and $\mathrm{mROE}$ : Mature-immature comparison test}

There was no evidence of a significant difference between the iROE $300 \mathrm{mg} / \mathrm{kg}$ group and the $\mathrm{mROE} 300 \mathrm{mg} /$ $\mathrm{kg}$ group according to the MANOVA results for the ipsilateral and contralateral sites $(\mathrm{F}[12.0,7.0]=1.808$, $P=0.221$, partial $\eta^{2}=0.756$ and $\mathrm{F}[12.0,7.0]=0.850$, $P=0.616$, partial $\left.\eta^{2}=0.593\right)$. The AUC values showed no evidence of significant differences between the groups injected at the ipsilateral and contralateral sites (MD 26.11; 95\% CI -5.56 to 57.77; $P=0.100$ and MD $24.44 ; 95 \%$ CI -6.15 to $55.02 ; P=0.099$, respectively). However, the LMEM showed a significant difference between the iROE $300 \mathrm{mg} / \mathrm{kg}$ and $\mathrm{mROE} 300 \mathrm{mg} / \mathrm{kg}$ groups for both the ipsilateral and contralateral sites $(\mathrm{F}[1,163.33]=8.211, P=0.005$, MD 0.13; 95\% CI 0.04 to $0.22 \mathrm{~F}[1,164.17]=9.198, P=0.003$ and $\mathrm{MD} 0.14 ; 95 \% \mathrm{CI}$ 0.05 to 0.23 ) (Fig. $4 a$ and $b$ ).

\section{Comparison of the antinociceptive effect of $\mathrm{RROE}$ versus the positive control}

There was no significant difference between the iROE $300 \mathrm{mg} / \mathrm{kg}$ and positive-control groups according to the MANOVA results for the ipsilateral and contralateral sites $\left(\mathrm{F}[12.0,7.0]=0.784, \quad P=0.661\right.$, partial $\eta^{2}=0.573$ and $F[12.0,7.0]=0.474, P=0.878$, partial $\eta^{2}=0.448$ ). However, the LMEM showed a significant difference between the iROE $300 \mathrm{mg} / \mathrm{kg}$ and positive-control groups for the ipsilateral and contralateral sites $(\mathrm{F}[1$,
183.08] $=4.178, P=0.043, \mathrm{MD} 0.08 ; 95 \% \mathrm{CI} 0.00$ to 0.16 and $\mathrm{F}[1,154.17]=20.55, P=0.001, \mathrm{MD} 0.12 ; 95 \% \mathrm{CI}$ 0.05 to 0.20 ) (Fig. 5a and b). The AUC values showed no evidence of significant differences between the groups injected at the ipsilateral and contralateral sites (MD 16.63; $95 \%$ CI -3.94 to $37.20 ; P=0.107$ and MD 15.74; 95\% CI -5.80 to $37.27 ; P=0.142$, respectively). There was no evidence of a significant difference between the iROE $300 \mathrm{mg} / \mathrm{kg}$ and positive-control groups, according to the MANOVA results, for the contralateral site $\left(\mathrm{F}[12.0,7.0]=0.474, P=0.878\right.$, partial $\left.\eta^{2}=0.448\right)$. However, the LMEM showed a significant difference between the iROE $300 \mathrm{mg} / \mathrm{kg}$ and positive-control groups.

\section{Assessment of motor impairment}

Compared with the control, iROE $300 \mathrm{mg} / \mathrm{kg}$ and $\mathrm{mROE}$ $300 \mathrm{mg} / \mathrm{kg}$ showed no significant effect on motor performance, as measured by the Rota-rod test, $30 \mathrm{~min}$ after the intraperitoneal injection of $\operatorname{ROE}(P=0.533)$. The time points at which the rats fell during the Rota-rod test were $107.83 \pm 11.65,104.33 \pm 10.74$, and $100.67 \pm 10.07$ in the control, iROE $300 \mathrm{mg} / \mathrm{kg}$, and $\mathrm{mROE} 300 \mathrm{mg} / \mathrm{kg}$ groups, respectively.

\section{Discussion}

This study is the first, to our knowledge, to present the antinociceptive effect of the intraperitoneal administration of immature $R$. occidentalis in rats with hyperalgesia induced by repeated intramuscular injection of acidic saline. Our findings showed that iROE exhibited an antinociceptive effect in a dose-dependent manner. This analgesic property of iROE was significantly 

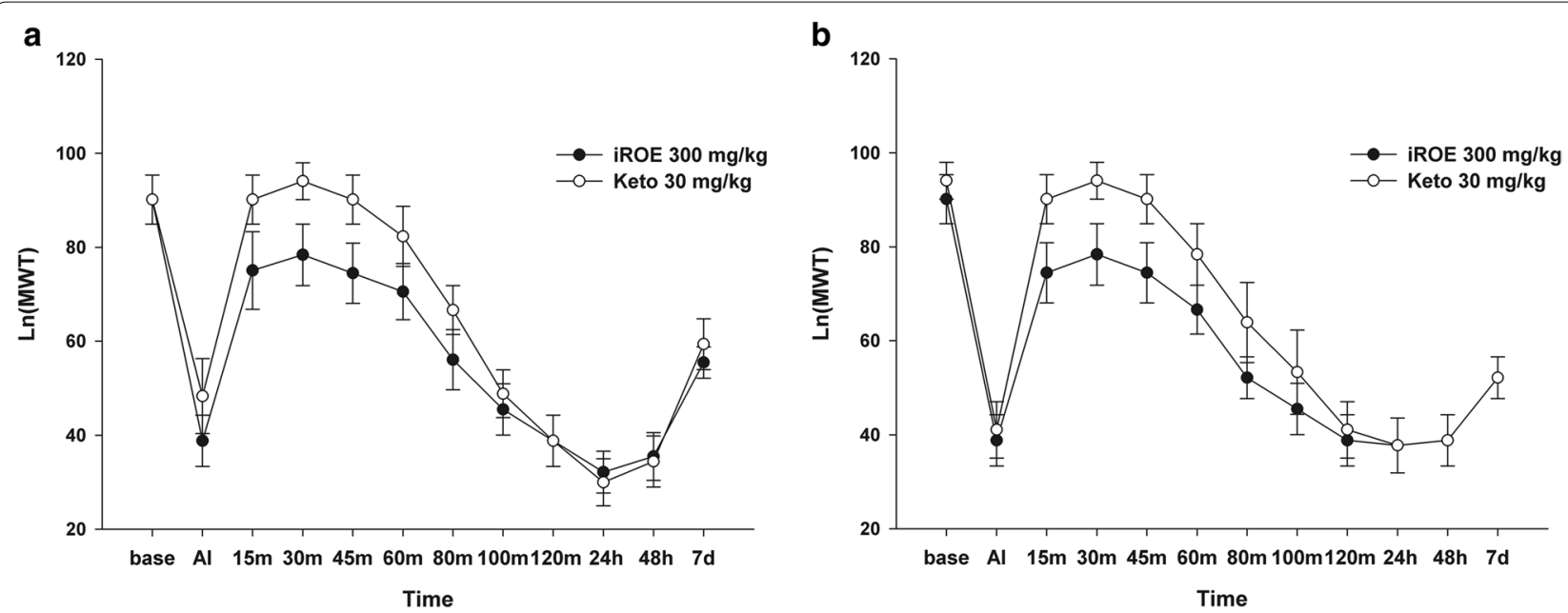

Fig. 5 Antinociceptive effect of immature Rubus occidentalis (iROE) versus $30 \mathrm{mg} / \mathrm{kg}$ of ketorolac (Keto). Al: immediately after injection. For statistical analysis, one-way Wilk's lambda multivariate analysis of variance and linear mixed-effects model was used

agonised by dexmedetomidine and antagonised by naloxone, mecamylamine, and yohimbine, which indicates the involvement of the $\alpha_{2}$-adrenergic, cholinergic, and opioid receptors. Moreover, iROE presented a superior antinociceptive potential to $\mathrm{mROE}$.

Since we observed that mROE exhibited an analgesic effect on chronic muscle pain in previous study [7], we would like to perform the study regarding iROE and compare between mROE and iROE in current study utilizing dose of $300 \mathrm{mg} / \mathrm{kg}$ with greatest analgesic effect. Although MANOVA revealed no evidence of a significant difference between the immature and mature groups, LMEM revealed a significant difference. We were unable to draw a firm conclusion about our result because MANOVA was used during the sample size calculation stage. However, based on the LMEM results, we can propose that immature $R$. occidentalis has a higher potential for analgesic effect than mature fruit. Besides, several studies on immature fruit provided support for our LMEM-based results. This may be the first and valuable evidence for the beneficial effect of immature black raspberry on chronic pain management.

The content of ellagic acid and anthocyanin, major components of ROE, depends on the ripening of the fruit $[5,17]$. Several studies have reported the different capacity of bioactive components in fruits including $R$. occidentalis. A study investigating the bioactive and pharmacokinetic characterisation of immature $R$. occidentalis reported that the immature fruit produced a high content of ellagic acid and vitamin $C$, presenting superior antioxidant activities [6]. Similar results have been observed for other Rubus species [6, 18]. Specifically, ellagic acid, a bioactive component in
Rubus species, was significantly higher in immature $R$. coreanus fruit than in mature fruit. Taghi et al. found that ellagic acid had central and peripheral antinociceptive effect in experimental pain model [19], which supports the analgesic effect of immature $R$. occidentalis based on our findings. In addition, $R$. coreanus fruit have potential applications owing to their antioxidative effects mediated via the scavenging of reactive oxygen species [20]. Therefore, it is suggested that components with the observed antioxidative activity are degraded during the ripening process. This theory can be supported by our results of the comparison between iROE and mROE: iROE showed the potential of superior analgesic effect to $\mathrm{mROE}$. The antioxidative property of $R$. occidentalis is worthy of consideration for the management of chronic pain. Oxidative stress refers to a condition that involves a disturbance in the balance between the production of oxidants and the reactivity of antioxidants; this balance is normally well-controlled [21]. There is strong evidence suggesting that oxidative stress is present in the skeletal muscle of patients with chronic diseases. Besides, since oxidative stress is intensively involved in the pathology of chronic fatigue, its levels are increased in chronic fatigue syndrome and are associated with clinical symptoms such as chronic musculoskeletal pain [22]. There is a causal link between oxidative stress and the pathogenesis of disease, and oxidative stress is now considered a major contributor to the development of numerous chronic diseases with pain [21]. Thus, the antioxidative effect of immature $R$. occidentalis can be utilised in chronic pain control, which supports its potential as an effective dietary complement for the management of chronic pain. 
Our results suggested that the $\alpha_{2}$-adrenergic and nicotinic cholinergic receptors were involved in the mechanism of antinociception. The involvement of the $\alpha_{2}$-adrenergic and nicotinic cholinergic receptors in the effect of iROE, as observed in the current study, was in agreement with the results of the previous study. Analgesic property of dexmedetomidine associated with $\alpha_{2}$ adrenoceptor is now well-established in perioperative pain management. It is useful for multimodal analgesic strategy in chronic pain patients for whom opioid anlagesics are ineffective [23]. Nicotinic acetylcholine receptors can be a therapeutic target for the chronic pain control [24]. Desensitization of the $\alpha 4 \beta 2^{*}$ nicotinic acetylcholine receptor may contribute to pain management efficacy and may be a mechanism for nicotinic agonistmediated analgesic effects [25]. Hence, immature R. occidentalis may be a promising candidate for multimodal analgesic therapy in patient suffering from chronic pain. It is interesting that current finding that opioid receptors were linked to the analgesic effect of iROE was contradictory to previous study's finding. This is a clear point of difference between mROE and iROE, which makes therapeutic approach specifically using iROE. Given the need to replace of opioid use in clinical field, iROE appears to be more beneficial than mROE in trems of a multimodal analgesic approach [18]. Non-steroidal antiinflammatory drugs, such as ketorolac, which is widely administered intravenously and intramuscularly, have the potential to replace opioids in pain management. We discovered that iROE of $300 \mathrm{mg} / \mathrm{kg}$ showed an expected analgesic effect compared to ketorolac, implying the potential clinical availability of immature $R$. occidentalis.

The current study has some limitations. First, the chronic pain model used in our study does not cause inflammation. Since there is strong evidence of the beneficial effect of $R$. occidentalis against inflammation, it would be valuable to obtain additional evidence by conducting further studies using the chronic inflammatory pain model. Second, despite the fact that we discussed the analgesic property of immature $R$. occidentalis in relation to its component, we did not conduct experiments at the molecular or cellular level. Further research that can provide evidence in this regard will be required. Third, although we compared the analgesic activity between $\mathrm{iROE}$ and $\mathrm{mROE}$, there was no further comparison between the two in terms of several beneficial properties such as an antiproliferative or anti-inflammatory effect. Future experiments based on an extended study design with a larger sample size may provide valuable evidence regarding the difference between immature and mature $R$. occidentalis. Finally, the current study administered ROE and test drugs intraperitoneally, which raises concern that this route may not be suitable for the experimental study of black raspberry. However, the intraperitoneal route is simple to set up, quick, and has a low stress impact on laboratory rodents [26], making it useful in pain research. Based on our findings from previous and current studies, future research that implements ROE via oral administration should take clinical applicability into account, which is supported by a study reporting the role of black raspberry in cancer and variations in fruit maturity stage [3].

Nonetheless, this study is valuable as an experimental study of $R$. occidentalis because it is based on a wellestablished and meticulously designed research protocol from our previous studies [7, 27]. We have made several attempts to investigate the effects of R.occidentalis in various pain models in greater depth. While previous studies presented evidence for ripe fruits, this study focused on presenting evidence for immature fruits as well as deriving new evidence by comparing immature and mature fruits. Our findings with $R$. occidentalis in both the acute and chronic pain models are expected to provide very useful evidence for clinical availability of $R$. occidentalis. This kind of research is characterizing the bioactivities of plant products and expanding their use in human healthcare.

\section{Conclusions}

Immature $R$. occidentalis showed antinociceptive activity against acid-induced chronic muscle pain. Its action may be mediated by the $\alpha_{2}$-adrenergic, nicotinic cholinergic, and opioid receptors and iROE displayed a superior antinociceptive tendency to mature ROE.

\section{Abbreviations \\ ANOVA: Analysis of variance; ARRIVE: Animal Research: Reporting In Vivo Experiments; IP: Intraperitoneal; iROE: Immature Rubus occidentalis extract; LMEM: Linear mixed-effects model; MANOVA: Multivariate analysis of vari- ance; MD: Mean difference; mROE: Mature Rubus occidentalis extract; MWT: Mechanical withdrawal threshold; ROE: Rubus occidentalis extract; Rpm: Rota- tions per minute.}

\section{Supplementary Information}

The online version contains supplementary material available at https://doi. org/10.1186/s12906-021-03491-z.

Additional file 1.

\section{Acknowledgements}

The authors thank II Young Jung and Jun Seop Ko for their technical support.

\section{Authors' contributions}

GJC contributed to the conception and design of the study, as well as the acquisition of data and drafting of the article. HK contributed to the conception and design of the study, the analysis and interpretation of data, and revision of the article. OHL, EJA, and YJC contributed to the acquisition of data and drafting of the article. FW, CWB, YHJ and JWK contributed to the conception 
and design of the study and revision of the article. All authors gave final approval of this version to be submitted.

\section{Funding}

This Research was supported by the Chung-Ang University Research Grants in 2019.

This research was supported by the Basic Science Research Program through the National Research Foundation of Korea (NRF) funded by the Ministry of Education, Science and Technology [Grant No. NRF-2020R1C1C1011263]. The Funding bodies play no role in the design of the study and collection, analysis, and interpretation of data and in writing the manuscript.

\section{Availability of data and materials}

The datasets used and analysed during the current study are available from the corresponding author upon reasonable request.

\section{Declarations}

\section{Ethics approval and consent to participate}

This work was approved by the Institutional Animal Care and Use Committee of Chung-Ang University (No. 2017-00107), and all experiments were performed in accordance with the National Institutes of Health Guide for the Care and Use of Laboratory Animals.

\section{Consent for publication}

Not applicable.

\section{Competing interests}

The authors declare that they have no competing interests.

\section{Author details}

'Department of Anesthesiology and Pain Medicine, Chung-Ang University College of Medicine, 84 Heukseok-ro, Dongjak-gu, Seoul 06911, Republic of Korea. ${ }^{2}$ Department of Anesthesia, Indiana University School of Medicine, Indianapolis, IN 46202, USA. ${ }^{3}$ Stark Neurosciences Research Institute, Indiana University School of Medicine, Indianapolis, IN 46202, USA. ${ }^{4}$ Gochang Berry \& Bio Food Research Institute, Gochang-gun, Jeollabuk-do, South Korea.

\section{Received: 28 August 2020 Accepted: 17 December 2021}

Published online: 11 January 2022

\section{References}

1. McBeth J, Jones K. Epidemiology of chronic musculoskeletal pain. Best Pract Res Clin Rheumatol. 2007;21(3):403-25.

2. Shetty K, McCue P. Phenolic antioxidant biosynthesis in plants for functional food application: integration of systems biology and biotechnological approaches. Food Biotechnol. 2003;17(2):67-97.

3. Johnson JL, Bomser JA, Scheerens JC, Giusti MM. Effect of black raspberry ( Rubus occidentalis L.) extract variation conditioned by cultivar, production site, and fruit maturity stage on colon cancer cell proliferation. J Agric Food Chem. 2011;59(5):1638-45

4. Dai J, Patel JD, Mumper RJ. Characterization of blackberry extract and its antiproliferative and anti-inflammatory properties. J Med Food. 2007;10(2):258-65.

5. Shin D, Chae K, Choi H, Lee S, Gim S, Kwon G, et al. Bioactive and pharmacokinetic characteristics of pre-matured black raspberry, rubus occidentalis. Italian J Food Sci. 2018;30(3):428-39.

6. Bhandary B, Lee HY, Back HI, Park SH, Kim MG, Kwon JW, et al. Immature rubus coreanus shows a free radical-scavenging effect and inhibits cholesterol synthesis and secretion in liver cells. Indian J Pharm Sci. 2012;74(3):211-6.

7. Choi GJ, Kang H, Kim WJ, Baek CW, Jung YH, Woo YC, et al. Rubus occidentalis alleviates hyperalgesia induced by repeated intramuscular injection of acidic saline in rats. BMC Complement Altern Med. 2016;16:202

8. Kilkenny C, Browne WJ, Cuthill IC, Emerson M, Altman DG. Improving bioscience research reporting: the ARRIVE guidelines for reporting animal research. PLoS Biol. 2010;8(6):e1000412.
9. Kang $\mathrm{H}$. Statistical messages from ARRIVE 2.0 guidelines. Korean. J Pain. 2021:34(1):1-3.

10. Hurley RW, Adams MC. Sex, gender, and pain: an overview of a complex field. Anesth Analg. 2008;107(1):309-17.

11. Shomer $\mathrm{NH}$, Allen-Worthington $\mathrm{KH}$, Hickman $\mathrm{DL}$, Jonnalagadda $\mathrm{M}$, Newsome JT, Slate AR, et al. Review of Rodent Euthanasia Methods. J Am Assoc Lab Anim Sci. 2020;59(3):242-53.

12. Sluka KA, Kalra A, Moore SA. Unilateral intramuscular injections of acidic saline produce a bilateral, long-lasting hyperalgesia. Muscle Nerve. 2001;24(1):37-46

13. Barocelli E, Calcina F, Chiavarini M, Impicciatore M, Bruni R, Bianchi A, et al. Antinociceptive and gastroprotective effects of inhaled and orally administered Lavandula hybrida Reverchon "Grosso" essential oil. Life Sci. 2004;76(2):213-23.

14. Viana AF, Maciel IS, Motta EM, Leal PC, Pianowski L, Campos MM, et al. Antinociceptive activity of trichilia catigua hydroalcoholic extract: new evidence on its dopaminergic effects. Evid-based Complement Alternative Med. 2011;2011:120820.

15. Leite Gde O, Fernandes CN, de Menezes IR, da Costa JG, Campos AR. Attenuation of visceral nociception by a-bisabolol in mice: investigation of mechanisms. Org Med Chem Lett. 2012;2(1):18.

16. Shou-Shi W, Ting-Ting S, Ji-Shun N, Hai-Chen C. Preclinical efficacy of Dexmedetomidine on spinal cord injury provoked oxidative renal damage. Ren Fail. 2015:37(7):1190-7.

17. Seo KH, Lee JY, Park JY, Jang GY, Kim HD, Lee YS, et al. Differences in antiinflammatory effect of immature and mature of Rubus coreanus fruits on LPS-induced RAW 264.7 macrophages via NF-KB signal pathways. BMC Complement Altern Med. 2019;19(1):89.

18. Chang RC, Rota C, Glover RE, Mason RP, Hong JS. A novel effect of an opioid receptor antagonist, naloxone, on the production of reactive oxygen species by microglia: a study by electron paramagnetic resonance spectroscopy. Brain Res. 2000;854(1-2):224-9.

19. Taghi Mansouri M, Naghizadeh B, Ghorbanzadeh B, Farbood Y. Central and peripheral antinociceptive effects of ellagic acid in different animal models of pain. Eur J Pharmacol. 2013;707(1-3):46-53.

20. Han SB, Kwon SS, Kong BJ, Kim KJ, Park SN. Antioxidative effect and tyrosinase inhibitory activity of the unripened fruit extract of Rubus coreanus Miquel. J Soc Cosmet Sci Korea. 2013;39(4):295-302.

21. Moylan JS, Reid MB. Oxidative stress, chronic disease, and muscle wasting. Muscle Nerve. 2007;35(4):411-29.

22. Kennedy G, Spence VA, McLaren M, Hill A, Underwood C, Belch JJ. Oxidative stress levels are raised in chronic fatique syndrome and are associated with clinical symptoms. Free Radic Biol Med. 2005;39(5):584-9.

23. Zhao Y, He J, Yu N, Jia C, Wang S. Mechanisms of Dexmedetomidine in Neuropathic Pain. Front Neurosci. 2020;14:330.

24. Hone AJ, McIntosh JM. Nicotinic acetylcholine receptors in neuropathic and inflammatory pain. FEBS Lett. 2018;592(7):1045-62.

25. Zhang J, Xiao YD, Jordan KG, Hammond PS, Van Dyke KM, Mazurov AA, et al. Analgesic effects mediated by neuronal nicotinic acetylcholine receptor agonists: correlation with desensitization of $a 4 \beta 2^{*}$ receptors. Eur J Pharm Sci. 2012:47(5):813-23.

26. Al Shoyaib A, Archie SR, Karamyan VT. Intraperitoneal Route of Drug Administration: Should it Be Used in Experimental Animal Studies? Pharm Res. 2019;37(1):12.

27. Choi GJ, Kang H, Kim WJ, Kwon JW, Kim BG, Choi YS, et al. Rubus occidentalis analgesic effect in a rat model of incisional pain. J Surg Res. 2016;206(1):223-30.

\section{Publisher's Note}

Springer Nature remains neutral with regard to jurisdictional claims in published maps and institutional affiliations. 